\title{
Effect of Boron Addition on Mechanical Properties of 60SiCr7 Stell
}

\author{
Hayrettin Düzcükoğlu and Selman Çetintürk
}

\begin{abstract}
Boron, as an alloy element, and its compounds are used in a wide range. It is determined that, boron and its compounds increases physical, chemical, mechanical and metallurgical properties of materials. With bronzing, materials get some the properties such as high hardness, high wear, less friction coefficient and high corrosion. In this study, effect on the mechanical properties of boron addition of $60 \mathrm{SiCr} 7$ steel were investigated. $60 \mathrm{SiCr} 7$ of spring steel, which is relatively low compared with treatment steel ductility by heat treatment in the treatment and in addition, various amounts of boron (ppm ratio) and improving the mechanical properties by alloying has been attempted. As a result of $15-30 \mathrm{ppm}$ added steel in tensile and fracture toughness has improved.
\end{abstract}

Index Terms-Boron, boron steels, mechanical testing.

\section{INTRODUCTION}

Boron steels, ideal after heat treatment at high hardness values have reached, also the friction and wear very good resistance against which they often harsh working conditions are suitable for the soil and road handling instruments and agricultural tools to the construction locations are recommended. Boron steels which high hardness and high wear resistance is alloy steels. The boron additive steels, easy to be processed and applied in very good mechanical properties after heat treatment are important features exhibitions. According to the same mechanical properties are cheaper than high alloy steels. With the same mechanical properties are cheaper than high alloy steels.

Boron additives steels accompanied by increasingly difficult economic conditions, the manufacturing industry is a good alternative. In addition to the benefits of economy and alloy conservation, boron steels offer significant advantages of better extradability and machinability compared with boron free steels of equivalent hardness [1]. Moreover, steels containing boron are also less susceptible to quench cracking and distortion during heat treatment. Consequently, boron containing carbon and alloy steels are widely used in automotive, constructional, and various other applications. Hardening depth of steel with the addition of the boron element, and has been shown to increase the ability to hardness. Boron over 8 ppm the content is considered as

Manuscript received September 26, 2014; revised January 6, 2015.

Hayrettin Düzcükoğlu is with Selcuk University, Technology Faculty, Mechanical Engineering Department, Konya, Turkey (e-mail: hayduzcukoglu@hotmail.com).

Selman Çetintürk is with Soylu Casting, Konya Organized Industrial Zone, Konya, Turkey. an alloying element. Boron is dissolved in ppm quantities in solid state in steel. The diameter of boron atom is $25 \%$ smaller than the diameter of iron atoms.

Boron can be made a solid solution with Iron. Boron can be found as both located and interstitial in $\alpha$-iron. Boron is very slightly soluble in $\alpha$ and $\gamma$ iron. The $\gamma$-iron is $260 \mathrm{ppm}$ at $1170{ }^{\circ} \mathrm{C}$, while the maximum solubility of boron is $80 \mathrm{ppm}$ at $910{ }^{\circ} \mathrm{C}$ in $\alpha$-iron [2]. Boron, the hardenability of the steel is alloying element which increases as the most effective. Boron element, mainly at the grain boundaries in the steel takes place and creates a very small grains sizes $\mathrm{Fe}_{23}(\mathrm{~B}, \mathrm{C})_{6}$.

It is well-known that a small amount of boron dramatically increases the hardenability of steels. This beneficial effect is attributed to grain boundary segregation previously mentioned, which retards the diffusional transformation of austenite to ferrite by lowering the interfacial energy at the austenite grain boundary [3].The segregation and precipitation of boron have been studied in thermo mechanically processed $0.2 \mathrm{C}, 0.6 \mathrm{Mn}$ and 0.5 Mo steels containing nominally 0,10,20, 50 and $100 \mathrm{ppm}$ boron. These steels were hot rolled in the laboratory, and their transformation behavior during subsequent water quenching was examined for different finish rolling temperature $\left(980^{\circ} \mathrm{C}\right.$ and $\left.870^{\circ} \mathrm{C}\right)$ and quenching temperatures $\left(730{ }^{\circ} \mathrm{C}\right.$ to $\left.950{ }^{\circ} \mathrm{C}\right)$. The results showed that in general, a free boron content of 10 to $20 \mathrm{ppm}$ will provide a boron hardenability increment similar to that for conventional quenched and tempered steels [4]. Boron additive, as properties metal high wear resistance, increased strength, high magnetic permeability, high elasticity, high surface protection, high temperature and corrosion resistance, high heat transfer, high adhesion and cohesion is increasing [5]. It is possible to say that boron minerals may be used in almost countless field as a result of today's technological advances. Boron minerals with the potential to use almost every field of industry be regarded as a basic raw materials for industry. Boron which as alloying elements in iron-based material is be used, must be below $0.1 \%$.

The last 10 years; in developed countries such as Germany, USA, Russia, Japan, China, with related to in steel use of boron have been done many studies. These improvements have found many uses at manufacture of materials as cast iron, stainless steel, the cutting tool, the manufacture of electron rods in nuclear reactors.

The effects of boron on the hardenability of steel are similar to those obtained with such common alloying elements as manganese, chromium, nickel, and molybdenum, but, unlike these elements, only a minute amount of boron is required. Since boron is relatively plentiful in this country, in many instances it can replace the aforementioned alloying elements, many of which must be imported at considerable expense from countries where political unrest is commonplace, making 
at least some sources of supply uncertain.

The wear resistance and fracture on digging edge of the excavator increasing demands and economic losses is remarkable. The digging edge of the excavator is driven by hydraulic mechanism. Then radius action makes a process the excavation. However, whole load occurred on tips of digging and come to the fore flexibility of materials [6]. Highlights the problem of this digging edge, rock or similar mass during excavation is damaged of digging edge such as fracture, wear etc.

In this study, TUBITAK, project number 7120768 TEYDEP study was conducted within the framework of cooperation between universities and industry. The adding ppm rate boron in $60 \mathrm{SiCr} 7$ spring steel order to determine the mechanical properties has been researched. The boron amount above of this ratio of boron, the high temperature embrittlement of steels and cast irons is caused by the harmful cracking. For these reasons, the boron is increased the depth of hardening added the rate of $0.007 \%$ in the steel, $0.005 \%$ for cast iron and graphite nucleation structure is said to help disperse uniformly [5], [7]. Many researchers have recommend, to increase hardened into the steel $5 \mathrm{ppm}$ from $15 \mathrm{ppm}$ to rate boron (maximum $30 \mathrm{ppm}$ )[7].

\section{MATERIAL AND METHOD}

\section{A. Experimental}

In this study, the chemical compound given in Table I were used $60 \mathrm{SiCr} 7$ spring steel ingot. During prototype castings, a lot of parameters recorded, such as boron and other alloying elements ratios, castings characterization and heat treatment temperature were investigated.

TABLE I: THE CHEMICAL COMPOSITION OF STEEL 60SICR7

\begin{tabular}{|c|c|c|c|c|c|}
\hline $\mathrm{C}$ & $\mathrm{Si}$ & $\mathrm{Mn}$ & $\mathrm{P}$ & $\mathrm{S}$ & $\mathrm{Cr}$ \\
\hline $0.57-$ & $1.5-$ & $0.70-$ & & & $0.20-$ \\
0.65 & 1.80 & 1.00 & $<0.030$ & $<0.030$ & 0.40 \\
\hline
\end{tabular}

To determine the tensile test results seen with the standard ASTM A 370, ISO 179/1 V notched Charpy test specimens were prepared in sand molds. For ppm values given in Table II, two specimen sand molds were prepared separately.

TABLE II: CONTRIBUTION RATE FOR THE TEST SAMPLES PPM BORON

\begin{tabular}{|c|c|c|c|c|c|c|c|}
\hline $\begin{array}{c}\text { ppm } \\
\text { rate }\end{array}$ & $\begin{array}{c}\text { without } \\
\text { boron }\end{array}$ & $10-19$ & $20-29$ & $30-39$ & $40-49$ & $50-59$ & $\begin{array}{c}60- \\
69\end{array}$ \\
\hline $\begin{array}{c}\text { Test } \\
\text { No }\end{array}$ & 1,2 & 3,4 & 5,6 & 7,8 & 9,10 & $\begin{array}{c}11, \\
12\end{array}$ & $\begin{array}{c}13, \\
14\end{array}$ \\
\hline
\end{tabular}

In this study, induction melting furnace with a capacity of $500 \mathrm{~kg}$ (Inductotherm $600 \mathrm{KW}$ ) (using melt $130 \mathrm{~kg}$ ) was carried out in non-vacuum environment. Before casting ppm ratio given in Table I to obtain the spectral analysis is controlled by sampling. Meanwhile, to isolate from the outside environment of casting were used the melt perlite powder. After obtaining the desired chemical content of melt casting process was performed with $10 \mathrm{~kg}$ pot. Meanwhile ferrobor material $18.2 \%$, from oxygen to protect boron (30gr) $99.9 \%$ pure aluminum was used.
Ferroboron is the lowest cost addition agent.

To develop the maximum hardenability effect, boron must be present in the steel in elemental form. Since boron has a strong affinity for oxygen and nitrogen, these elements either must be removed or controlled for boron to have its full hardenability effect. Accordingly, it has been the general practice to add boron to steel with titanium and zirconium present to protect the boron from nitrogen, and aluminum to protect boron from oxygen. In addition to effecting deoxidation and providing protection of boron from oxygen, aluminum is an effective grain refiner in production of ingot cast fine-grained steel. However, aluminum or alumina residuals in the steel may be detrimental to surface quality and other desired properties in the cast steel. The boron alloying additive of this invention, in addition to containing small quantities of boron, contains as essential constituents substantial amounts of titanium and rare earth metals which protect the boron from nitrogen and oxygen

In the same manner from Nitrogen to protect boron $70 \%$ (43gr) titanium used. In order to raise the efficiency of the action of boron on the hardness of steel it is necessary to add titanium, which possesses a higher affinity for nitrogen than boron and also forms nitrides in liquid phase. So, sufficient Ti was added to combine with the nitrogen to forming TiN Titanium and aluminum ratio is constant for every $30 \mathrm{~kg}$ pot while $18.2 \%$ ferrobor to obtain the values in Table II were prepared at different rates. During cast the first aluminum later titanium added. After this process the samples according to Table II was casted.

During casting, for accuracy of boron alloy and other values was checked by spectral analysis. After casting tensile and impact test specimens was carried out in accordance with standards machined. Mechanical properties of steels are showed that they strongly connected to their microstructure obtained after heat treatments that are generally performed in order to achieve a good hardness and/or tensile strength with different sufficient ductility In addition to the high yield strength properties to enhance the toughness, austempering was carried out. $60 \mathrm{SiCr} 7$ spring steel, Ac3 temperature about $200^{\circ} \mathrm{C}\left(930^{\circ} \mathrm{C}\right)$ were made austenitic. After oil-immersed level cooling $\mathrm{Ms}+70^{\circ} \mathrm{C}\left(400^{\circ} \mathrm{C}\right)$, and waiting for about 1.5 hours, later $20^{\circ} \mathrm{C} / \mathrm{s}$ to the room temperature cooled, bainitic structure has been generated. The toughness values of high strength spring steels can be increased by heat treatment, and the development of the production of digging edge will be able

\section{RESULTS AND DISCUSSION}

\section{A. Experimental Results}

In order to evaluate the efficiency of the boron action, hardness of all produced steels was investigated. As shown in Fig. 1, the test specimens were surface hardness after heat treatment. Test samples from three different areas were measured and their average hardness was evaluated. In our tests Brinell (HB) method is used for hardness. Brinnels hardness test was carried out using a standard hardness testing machine. The steel ball diameter of the indenter was $10 \mathrm{~mm}$ and the load applied was 3,000 kg. Hardness values were measured at three different places across the cross section of 
test piece and the average of three values were noted.

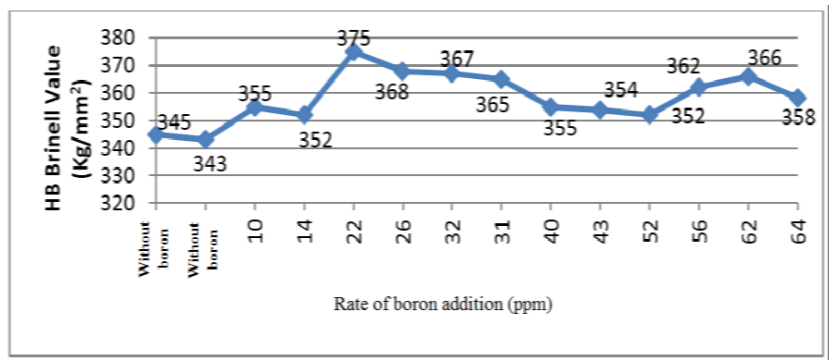

Fig. 1. Results of hardness values.

As shown in Fig. 1, without boron samples after heat treatment were be 343 to $345 \mathrm{HB}$. In particular, hardness values of the sample 20-30ppm boron addition were highest values obtained. However, the boron addition over $30 \mathrm{ppm}$ showed to decrease in hardness values. Again showed a slight increase in the amount of $50 \mathrm{ppm}$ boron. The hardness of boron addition test samples were higher compared to samples without boron. An outstanding feature of boron steels is the improvement in hardenability produced by the addition of even a minute quantity of boron. It is generally accepted that a hardenability peak is reached when the quantity of boron is between 30 and $15 \mathrm{ppm}$. In an excessive amount of boron $(>30 \mathrm{ppm})$ is present, the boron constituents become segregated in the austenite grain boundaries, which not only lowers hardenability, but also may decrease toughness, cause embrittlement and produce hot shortness. The effect of boron on hardenability also depends on the amount of carbon in the steel. The effect of boron increases in inverse proportion to the percentage of carbon present.

Notched impact test results are showed in Fig. 2. In Fig. 2 , the impact test results values 34 joules of $35-45 \mathrm{ppm}$ boron addition test sample has been in the highest. The higher ppm boron-addition value increase, the degreaser impact value showed declines. $60 \mathrm{ppm}$ addition boron samples has had the lowest impact energy.

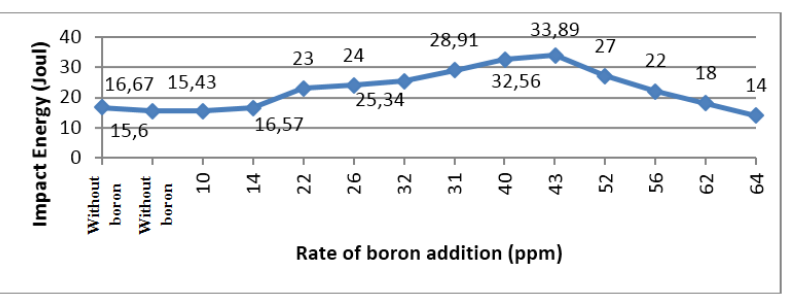

Fig. 2. Notch impact test results.

In Fig. 3 shows the results of tensile testing of the test sample. As shown in Fig. 3, 10-30 ppm boron addition samples both tensile strength and the yield stress have remained at a high value, but showed a tendency to a decrease after 30ppm.

Tensile strength test; this test was carried out on an Universal Testing Machine of $60 \mathrm{t}$ capacity in mechanical testing laboratory at Selcuk University. The load on the test specimen was applied steadily till fracture occurs.

Fig. 4 shows the elongation values of test samples. The highest elongation values in the 10-20 ppm boron addition sample were observed. The average $20 \mathrm{ppm}$ boron addition samples very small amount showed a decreasing trend.

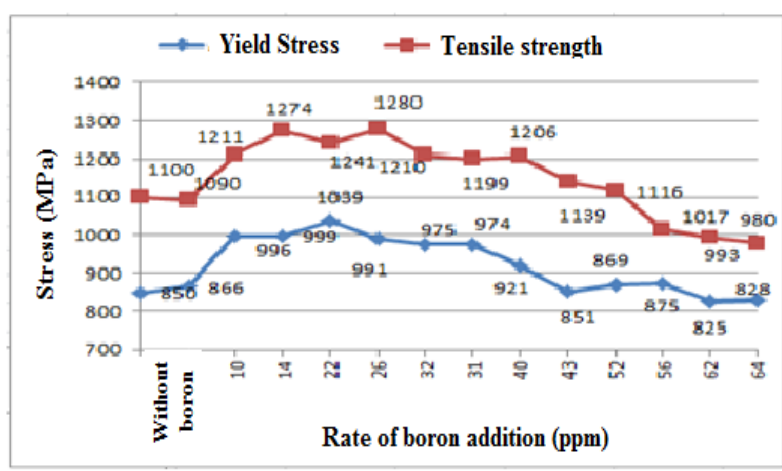

Fig. 3. Tensile strength result.

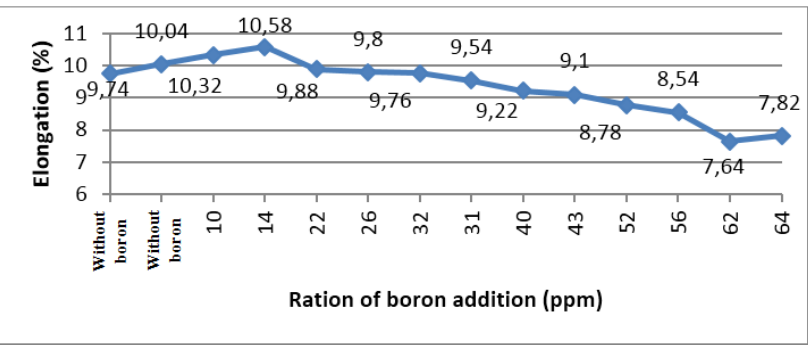

Fig. 4. Elongation \% results.

The elongation and contraction section begins to decrease after from $20 \mathrm{ppm}$ boron as shown in Fig. 3. Resistance is increasing up to $20 \mathrm{ppm}$ boron. However, steady of the ductility remain significant. It is important that $15-30 \mathrm{ppm}$ addition samples increased the tensile strength and yield strength, no decrease of ductility

The basic effect of boron on in the steel is the enhancement of hardenability, which is evident already at a very small concentration, of the degree of $20 \mathrm{ppm}$ boron. It is added to unalloyed and low alloyed steels for the hardness level enhancement through the hardenability. Even in the small quantity of the degree of size up to $40 \mathrm{ppm}$, boron gives the same effect of the hardenability enhancement as other more expensive elements which must be added in much bigger quantity.

Boron steels are used for a variety of applications, as a wear material and as a high strength structural steel. Examples include punching tools, spades, and knives, saw blades, safety beams in vehicles etc.

The boron-free steel in $60 \mathrm{SiCr} 7$ was added to determine titanium and aluminum the optimal ratio of boron. To protect combines with nitrogen of boron the titanium additional combines with nitrogen TiN (Titanium Nitride) were observed. SEM investigation it was found (Fig. 5).

Carbon-manganese-boron steels are generally specified as replacements for alloy steels for reasons of cost: C-Mn-B steels are far less expensive than alloy steels of equivalent hardenability. Applications for these steels include earth scraper segments, track links, rollers, drive sprockets, axle components and crankshafts.

Boron alloy steels are specified when the base composition meets mechanical property requirements (toughness, wear resistance, etc.), but hardenability is insufficient for the intended section size. Rather than call for a more highly alloyed and therefore more expensive steel, a user may simply 
specify the corresponding boron grade, thereby ensuring suitable hardenability.
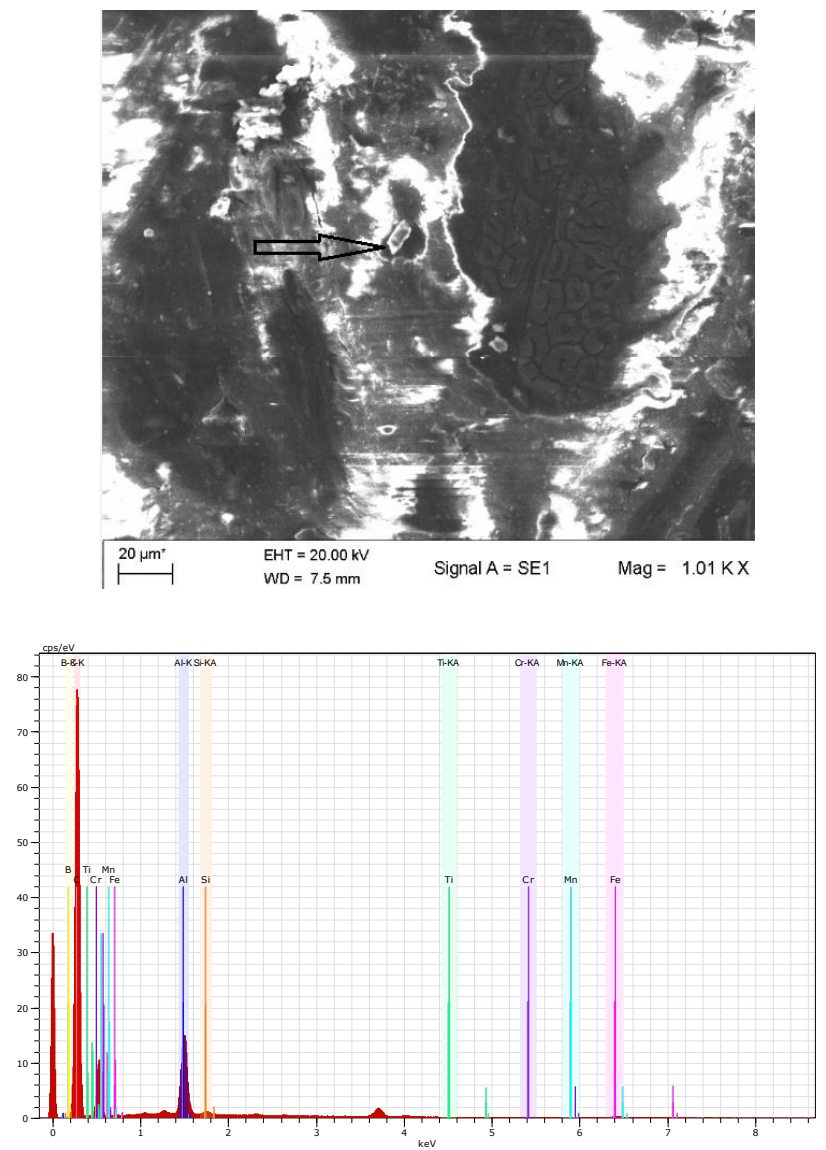

Fig. 5. SEM and EDS investigation for 30ppm.

\section{CONCLUSION AND DISCUSSION}

In this study, in $60 \mathrm{SiCr} 7$ steel of ppm boron addition range; hardenability, impact toughness and tensile stress that the optimum effect was studied to determine the amount of boron. The data obtained from the mechanical tests results, usually the boron addition were increased steel yields and tensile strength. 15-30 ppm boron addition hardness and impact resistance values were obtained in the optimum value.

With increasing addition of boron to the extent of about 20ppm, both the tensile strength and hardness values increase. This is attributed to carbide forming tendency of the boron

Also increased ductility. Steel produced shows the effectiveness of the boron additive. Improvement of steel grade $60 \mathrm{SiCr} 7$ can be carried out by addition of boron. The results indicate that the addition of B up to $15-30 \mathrm{ppm}$ increase sharply both the yield and ultimate tensile strength. Addition of boron improves impact toughness at $25^{\circ} \mathrm{C}$ and enhances the martensite formation. The activation energies of carbon migration through martensite phase decreases with the increase of boron content due to its positive effect on the crystallinity of martensite phase.

In 40 ppm boron addition samples; tensile, yield, elongation and hardness value was observed to decreasing trend. With increasing addition of boron, both the tensile strength and hardness values are decreased. Decrease in tensile strength is more drastic when compared with hardness. The most important reason for the increase in yield and tensile values, as a result reduction of particle size increase of the total grain boundary surface is believed to cause from blocking the movement of dislocation.

Realization casting process in non-vacuum induction furnace, the process is difficult to take control. Thus, when casting as much as possible to close to the melt furnace. The casting process should be completed in a short time. However, heat treatment parameters of boron addition products has been shown to affect results test.

\section{ACKNOWLEDGEMENT}

This publication Tubitak Teydep 1507 project Soylu Cating Industry Trade Limited Company and Selcuk University Scientific Research Project (BAP) are grateful for their support.

\section{REFERENCES}

[1] S. N. Ghali, H. S. El-Faramawy, and M. M. Eissa, "Influence of boron additions on mechanical properties of carbon steel," Journal of Minerals and Materials Characterization and Engineering, vol. 11, no. 10, pp. 995-999, Oct. 2012.

[2] C. Çarboğa, "Effect of low carbon steel on microstructure and mechanical properties of boron additions," $\mathrm{PhD}$ Thesis, Institute of Science and Technology, GÜ, Ankara, p. 78, 2010.

[3] F. Han, B. Hwang, D. Suh, Z. Wang, D. Lee, and S. J. Kim, "Effect of molybdenum and chromium on hardenability of low-carbon boronadded steels," Metals and Materials International, vol. 14, no. 6, pp. 667-672, 2008.

[4] K. A. Taylor and S. S. Hansen, "The boron hardenability effect in thermo mechanically processed, direct-quenched 0, 2 Pct steels," Metallurgical Transactions, 21A, Bethlehem, 1990, pp. 1697-1708.

[5] A. Çalık, "Machinery and use of boron in the metallurgical industry," in Proc. International Boron Symposium, Suleyman Demirel Univ., 2325 Oct., Isparta, Turkey, pp. 128-132, 2004.

[6] Y. Ercan and H. Sar1, "The basic parameters of the hydraulic excavator design will be the basis for determining the optimum technical and economical selection of hydraulic components," in Proc. 4th National Congress of Hydraulic and Pneumatic, 1-4 Dec. Izmir, Turkey, 2005, pp. 337-353.

[7] Z. Taş, "Nb-V alloy microstructure in boron steel - the relationship between the mechanical properties," Erciyes University Journal of the Institute of Science, Kayseri, Turkey, pp. 152-160, 2006.

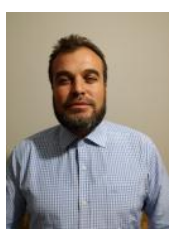

Hayrettin Düzcükoğlu was born in 1969, who is currently an associate professor at Selcuk University, Faculty of Techonology, Department of Mechanical Engineering. His main research interests include mechatronics, wear, tribology, gear. 